\title{
Sophus Lie: A Real Giant in Mathematics
}

\section{by Lizhen $\mathrm{Ji}^{*}$}

\begin{abstract}
This article presents a brief introduction to the life and work of Sophus Lie, in particular his early fruitful interaction and later conflict with Felix Klein in connection with the Erlangen program, his productive writing collaboration with Friedrich Engel, and the publication and editing of his collected works.
\end{abstract}

\section{Contents}

1 Introduction . . . . . . . . . . . . . . 66

2 Some General Comments on Lie and His Impact 67

3 A Glimpse of Lie's Early Academic Life . . . 68

4 A Mature Lie and His Collaboration with Engel 69

5 Lie's Breakdown and a Final Major Result . . 71

6 An Overview of Lie's Major Works . . . . . . 72

7 Three Fundamental Theorems of Lie in the Lie Theory . . . . . . . . . . . . . . . . . . 73

8 Relation with Klein I: The Fruitful Cooperation . . . . . . . . . . . . . . 74

9 Relation with Klein II: Conflicts and the Famous Preface . . . . . . . . . . . . . 74

10 Relations with Others . . . . . . . . . . . 77

11 Collected Works of Lie: Editing, Commentaries and Publication . . . . . . . . . . . 78

\section{Introduction}

There are very few working mathematicians and physicists who have not heard of Lie groups or Lie algebras and made use of them in some way or an-

* Department of Mathematics, University of Michigan, Ann Arbor, Mich., U.S.A.

E-mail: lji@umich.edu other. If we treat discrete or finite groups as special (or degenerate, zero-dimensional) Lie groups, then almost every subject in mathematics uses Lie groups. As H. Poincaré told Lie [25] in October 1882, "all of mathematics is a matter of groups." It is clear that the importance of groups comes from their actions. For a list of topics of group actions, see [17].

Lie theory was the creation of Sophus Lie, and Lie is most famous for it. But Lie's work is broader than this. What else did Lie achieve besides his work in the Lie theory? This might not be so well known. The differential geometer S. S. Chern wrote in 1992 that "Lie was a great mathematician even without Lie groups" [7]. What did and can Chern mean? We will attempt to give a summary of some major contributions of Lie in $\S 6$.

One purpose of this article is to give a glimpse of Lie's mathematical life by recording several things which I have read about Lie and his work. Therefore, it is short and emphasizes only a few things about his mathematics and life. For a fairly detailed account of his life (but not his mathematics), see the full length biography [27].

We also provide some details about the unfortunate conflict between Lie and Klein and the famous quote from Lie's preface to the third volume of his books on transformation groups, which is usually only quoted without explaining the context. The fruitful collaboration between Engel and Lie and the publication of Lie's collected works are also mentioned.

We hope that this article will be interesting and instructive to the reader and might serve as a brief introduction to the work and life of Lie. 


\section{Some General Comments on Lie and His Impact}

It is known that Lie's main work is concerned with understanding how continuous transformation groups provide an organizing principle for different areas of mathematics, including geometry, mechanics, and partial differential equations. But it might not be well known that Lie's collected works consist of 7 large volumes of the total number of pages about 5600. (We should keep in mind that a substantial portion of these pages are commentaries on his papers written by the editors. In spite of this, Lie's output was still enormous.) Probably it is also helpful to keep in mind that Lie started to do mathematics at the age of 26 and passed away at 57 . Besides many papers, he wrote multiple books, which total over several thousands of pages as well. According to Lie, only a part of his ideas had been put down into written form. In an autobiographic note [9, p. 1], Lie wrote:

\begin{abstract}
My life is actually quite incomprehensible to me. As a young man, I had no idea that I was blessed with originality. Then, as a 26 -year-old, I suddenly realized that I could create. I read a little and began to produce. In the years 1869-1874, I had a lot of ideas which, in the course of time, I have developed only very imperfectly.

In particular, it was group theory and its great importance for the differential equations which interested me. But publication in this area went woefully slow. I could not structure it properly, and I was always afraid of making mistakes. Not the small inessential mistakes... No, it was the deep-rooted errors I feared. I am glad that my group theory in its present state does not contain any fundamental errors.
\end{abstract}

Lie was a highly original and technically powerful mathematician. The recognition of the idea of Lie groups (or transformation groups) took time. In 1870s, he wrote in a letter [26, p. XVIII]:

\begin{abstract}
If I only knew how to get the mathematicians interested in transformation groups and their applications to differential equations. I am certain, absolutely certain in my case, that these theories in the future will be recognized as fundamental. I want to form such an impression now, since for one thing, I could then achieve ten times as much.
\end{abstract}

In 1890, Lie was confident and wrote that he strongly believed that his work would stand through all times, and in the years to come, it would be more and more appreciated by the mathematical world.

Eduard Study was a privatdozent (lecturer) in Leipzig when Lie held the chair in geometry there. In 1924, the mature Eduard Study summarized Lie as follows [26, p. 24]:

Sophus Lie had the shortcomings of an autodidact, but he was also one of the most brilliant mathematicians who ever lived. He possessed something which is not found very often and which is now becoming even rarer, and he possessed it in abundance: creative imagination. Coming generations will learn to appreciate this visionary's mind better than the present generation, who can only appreciate the mathematicians' sharp intellect. The allencompassing scope of this man's vision, which, above all, demands recognition, is nearly completely lost. But, the coming generation [...] will understand the importance of the theory of transformation groups and ensure the scientific status that this magnificent work deserves.

What Lie studied are infinitesimal Lie groups, or essentially Lie algebras. Given what H. Weyl and E. Cartan contributed to the global theory of Lie groups starting around the middle of 1920s and hence made Lie groups one of the most basic and essential objects in modern (or contemporary) mathematics, one must marvel at the above visionary evaluation of Lie's work by Study. For a fairly detailed overview of the historical development of Lie groups with particular emphasis on the works of Lie, Killing, E. Cartan and Weyl, see the book [14].

Two months after Lie died, a biography of him appeared in the American Mathematical Monthly [12]. It was written by George Bruce Halsted, an active mathematics educator and a mathematician at the University of Texas at Austin, who taught famous mathematicians like R. L. Moore and L. E. Dickson. Reading it more than one hundred years later, his strong statement might sound a bit surprising but is more justified than before, "[...] the greatest mathematician in the world, Sophus Lie, died [...] His work is cut short; his influence, his fame, will broaden, will tower from day to day."

Probably a more accurate evaluation of Lie was given by Engel in a memorial speech on Lie [9, p. 24] in 1899:
If the capacity for discovery is the true measure of a mathematician's greatness, then Sophus Lie must be ranked among the foremost mathemati- cians of all time. Only extremely few have opened up so many vast areas for mathematical research and created such rich and wide-ranging methods as he [...] In addition to a capacity for discovery, we expect a mathematician to posses a penetrat- ing mind, and Lie was really an exceptionally gifted mathematician [...] His efforts were based on tack- ling problems which are important, but solvable, and it often happened that he was able to solve problems which had withstood the efforts of other eminent mathematicians.

In this sense, Lie was a giant in mathematics for his deep and original contribution to mathematics, and is famous not for other reasons. (One can easily think of several mathematicians, without naming them, who are famous for various things besides mathematics). Incidentally, he was also a giant in the physical sense. There are some vivid descriptions of Lie by people such as E. Cartan [1, p. 7], Engel [27, p. 312], and his physics colleague Ostwald at Leipzig [27, p. 396]. See also [27, p. 3]. For some interesting discussions on the relations between giants 
and scientists, see [11, pp. 163-164, p. 184] and [22, pp. 9-13].

\section{A Glimpse of Lie's Early Academic Life}

Lie was born on December 17, 1842. His father, Johann Herman Lie, was a Lutheran minister. He was the youngest of the six children of the family. Lie first attended school in the town of Moss in South Eastern Norway and on the eastern side of the Oslo Fjord. In 1857 he entered Nissen's Private Latin School in Christiania, which became Oslo in 1925. At that time, he decided to pursue a military career, but his poor eyesight made this impossible, and he entered University of Christiania to pursue a more academic life.

During his university time, Lie studied science in a broad sense. He took mathematics courses and attended lectures by teachers of high quality. For example, he attended lectures by Sylow in $1862 .{ }^{1}$

Though Lie studied with some good mathematicians and did well in most courses, on his graduation in 1865 , he did not show any special ability for mathematics or any particular liking for it. Lie could not decide what subject to pursue and he gave some private lessons and also volunteered some lectures for a student union while trying to make his decision. He knew he wanted an academic career and thought for a while that astronomy might be the right topic. He also learnt some mechanics, and wondered about botany, zoology or physics. Lie reached the not-so-tender age of 26 in 1868 and was still not sure what he should pursue as a career. But this year was a big turning point for him.

In June 1868, the Tenth Meeting of Scandinavian Natural Sciences was held in Christiania. It attracted 368 participants. Lie attended many lectures and was particularly influenced by the lecture of a former student of the great French geometer Michel Chasles, which referred to works of Chasles, Möbius, and Plücker.

It seems that the approaching season, the autumn of 1868, became one long continuing period of work for Sophus Lie, with his frequent borrowing of books from the library. In addition to Chasles, Möbius and Plücker, Lie discovered the Frenchman Poncelet, the Englishman Hamilton, and the Italian Cremona, as

\footnotetext{
${ }^{1}$ Ludwig Sylow (1832-1918) was Norwegian, like Lie. He is now famous and remembered for the Sylow subgroups. At that time, he was not on the permanent staff of the university of Christiania, but he was substituting for a regular faculty member and taught a course. In this course, he explained Abel's and Galois' work on algebraic equations. But it seems that Lie did not understand or remember the content of this course, and it was Klein who re-explained these theories to him and made a huge impact on Lie's mathematical life.
}

well as others who had made important contributions to algebraic and analytic geometry.

Lie plowed through many volumes of the leading mathematical journals from Paris and Berlin, and in the Science Students Association he gave several lectures during the spring of 1869 on what he called his "Theory of the imaginaries", and on how information on real geometric objects could be transferred to his "imaginary objects".

Sophus Lie wrote a paper on his discovery. The paper was four pages long and it was published at his own expenses. ${ }^{2}$ After this paper was translated into German, it was published in the leading mathematics journal of the time, Crelle's Journal. ${ }^{3}$ With this paper, he applied to the Collegium for a travel grant and received it. Then he left for Berlin in September 1869 and begun his glorious and productive mathematical career.

There were several significant events in Berlin for Lie on this trip. He met Felix Klein and they immediately became good friends. They shared common interests and common geometric approaches, and their influence on each other was immense. Without this destined (or chance) encounter, Lie and Klein might not have been the people we know.

Lie also impressed Kummer by solving problems which Kummer was working on. This gave him confidence in his own power and originality. According to Lie's letter to his boyfriend [26, p. XII]:

\begin{abstract}
Today I had a triumph which I am sure you will be interested to hear about. Professor Kummer suggested that we test our powers on a discussion of all line congruences of the 3rd degree. Fortunately, a couple of months ago, I had already solved a problem which was in a way special of the above, but was nevertheless much more general. ...I regard this as a confirmation of my good scientific insight that I, from the very first, understood the value of findings. That I have shown both energy and capability in connection with my findings; that I know.
\end{abstract}

In the summer of 1970, Lie and Klein visited Paris and met several important people such as Jordan and Darboux. The interaction with Jordan and Jordan's new book on groups had a huge influence on both of them. This book by Jordan contained more

2 The publication of this paper is unusual also by today's standard. According to [2], "His first published paper appeared in 1869. It gives a new representation of the complex plane and uses ideas of Plücker. But Lie had difficulties in getting these ideas published by the Academy in Christiania. He was impatient. Professor Bjerknes asked for more time to look at the paper, but Professor Broch returned it after two days - saying he had understood nothing! However, three other professors - who probably understood the material even less - supported publication. This happened as a result of influence by friends of Lie."

${ }^{3}$ The German version of this paper is still only 8 pages long, but in his collected works edited by Engel and Heegaard, there are over 100 pages of commentaries devoted to it. 
than an exposition of Galois theory and can be considered a comprehensive discussion of how groups were used in all subjects up to that point. For Klein and Lie, it was an eye opener. Besides learning Galois theory, they started to realize the basic and unifying role groups would play in geometry and other parts of mathematics. In some sense, the trips with Klein sealed the future research direction of Lie. Klein played a crucial role in the formative years of Lie, and the converse is also true. We will discuss their interaction in more detail in $\S 8$ and $\S 9$.

At the outbreak of the Franco-Prussian war in July, Klein left, and Lie stayed for one more month and then decided to hike to Italy. But he was arrested near Fontainebleau as he was suspected of being a spy and spent one month in jail. Darboux came and freed him. In [8], Darboux wrote:

True, in 1870 a misadventure befell him, whose consequences I was instrumental in averting. Surprised at Paris by the declaration of war, he took refuge at Fontainebleau. Occupied incessantly by the ideas fermenting in his brain, he would go every day into the forest, loitering in places most remote from the beaten path, taking notes and drawing figures. It took little at this time to awaken suspicion. Arrested and imprisoned at Fontainebleau, under conditions otherwise very comfortable, he called for the aid of Chasles, Bertrand, and others; I made the trip to Fontainebleau and had no trouble in convincing the procureur impérial; all the notes which had been seized and in which figured complexes, orthogonal systems, and names of geometers, bore in no way upon the national defenses.

Afterwards, Lie wrote to his close friend [26, p. $\mathrm{XV}]$, "except at the very first, when I thought it was a matter of a couple of days, I have taken things truly philosophically. I think that a mathematician is well suited to be in prison."

In fact, while he was in prison, he worked on his thesis and a few months later, he submitted his thesis, on March 1871. He received his doctorate degree in July 1872, and accepted a new chair at the university of Christiania set up for him by the Norwegian National Assembly. It was a good thesis, which dealt with the integration theory of partial differential equations. After his thesis, Lie's mathematics talent was widely recognized and his mathematical career was secured.

When Lie worked on his thesis with a scholarship from the University of Christiania, he needed to teach at his former grammar school to supplement his income. With this new chair, he could devote himself entirely to mathematics. Besides developing his work on transformation groups and working with Klein towards the formulation of the Erlangen program, Lie was also involved in editing with his former teacher Ludwig Sylow the collected works of Abel. Since Lie was not familiar with algebras, especially with Abel's works, this project was mainly carried out by Sylow.
But locating and gathering manuscripts of Abel took a lot of effort to both men, and the project took multiple years.

In his personal life, Lie married Anna Birch in 1874, and they had two sons and a daughter.

Lie published several papers on transformation groups and on the applications to integration of differential equations and he established a new journal in Christiania to publish his papers, but these papers did not receive much attention. Because of this, Lie started to work on more geometric problem such as minimal surfaces and surfaces of constant curvature.

Later in 1882 some work by French mathematicians on integration of differential equations via transformation groups motivated Lie to go back to his work on integration of differential equations and theories of differential invariants of groups.

\section{A Mature Lie and His Collaboration with Engel}

There were two people who made, at least contributed substantially to make, Lie the mathematician we know today. They were Klein and Engel. Of course, his story with Klein is much better known and dramatic and talked about, but his interaction with Engel is not less important or ordinary.

In the period from 1868 to 1884 , Lie worked constantly and lonely to develop his theory of transformation groups, integration problems, and theories of differential invariants of finite and infinite groups. But he could not describe his new ideas in an understandable and convincing way, and his work was not valued by the mathematics community. Further, he was alone in Norway and no one could discuss with him or understand his work.

In a letter to Klein in September 1883 [9, p. 9], Lie wrote that "It is lonely, frightfully lonely, here in Christiania where nobody understands my work and interests."

Realizing the seriousness of the situation of Lie and the importance of summarizing in a coherent way results of Lie and keeping him productive, Klein and his colleague Mayer at Leipzig decided to send their student Friedrich Engel to assist Lie. Klein and Mayer knew that without help from someone like Engel, Lie could not produce a coherent presentation of his new novel theories.

Like Lie, Engel was also a son of a Lutheran minister. He was born in 1861, nineteen years younger than Lie. He started his university studies in 1879 and attended both the University of Leipzig and the University of Berlin. In 1883 he obtained his doctorate degree from Leipzig under Mayer with a thesis on contact transformations. After a year of military service in Dresden, Engel returned to Leipzig in the 
spring of 1884 to attend Klein's seminar in order to write a Habilitation. At that time, besides Klein, Mayer was probably the only person who understood Lie's work and his talent. Since contact transformations form one important class in Lie's theories of transformation groups, Engel was a natural candidate for this mission. Klein and Mayer worked together to obtain a stipend from the University of Leipzig and the Royal Society of Sciences of Saxony for Engel so that he could travel to work with Lie in Christiania.

In June 1884, Lie wrote a letter to Engel [9, p. 10],

From 1871-1876, I lived and breathed only transformation groups and integration problems. But when nobody took any interest in these things, I grew a bit weary and turned to geometry for a time. Now just in the last few years, I have again taken up these old pursuits of mine. If you will support me with the further development and editing of these things, you will be doing me a great service, especially in that, for once, a mathematician finally has a serious interest in these theories. Here in Christiania, a specialist like myself is terribly lonely. No interest, no understanding.

According to a letter of Engel in the autumn of 1884 after meeting Lie [27, p. 312]:

The goal of my journey was twofold: on one hand, under Lie's own guidance, I should become immersed in his theories, and on the other, I should exercise a sort of pressure on him, to get him to carry on his work for a coherent presentation of one of his greater theories, with which I should help him apply his hand.

Lie wanted to write a major comprehensive monograph on transformation groups, not merely a simple introduction to his new theory. It "should be a systematic and strict-as-possible account that would retain its worth for a long time" [9, p. 11].

Lie and Engel met twice every day, in the morning at the apartment of Engel and in the afternoon at Lie's apartment. They started with a list of chapters. Then Lie dictated an outline of each chapter and Engel would supply the detail. According to Engel [9, p. 11],

Every day, I was newly astonished by the magnificence of the structure which Lie had built entirely on his own, and about which his publications, up to then, gave only a vague idea. The preliminary editorial work was completed by Christmas, after which Lie devoted some weeks to working through all of the material in order to lay down the final draft. Starting at the end of January 1885, the editorial work began anew; the finished chapters were reworked and new ones were added. When I left Christiania in June of 1885 , there was a pile of manuscripts which Lie figured would eventually fill approximately thirty printer's sheets. That it would be eight years before the work was completed and the thirty sheets would become one hundred and twenty-five was something neither of us could have imagined at that time.

Lie and Engel worked intensively over the nine month period when Engel was there. This collabora- tion was beneficial to both parties. To Engel, it was probably the best introduction to Lie theories and it served his later mathematical research well. According to Kowalewski, a student of Lie and Engel, [9, p. 10], "Lie would never have been able to produce such an account by himself. He would have drowned in the sea of ideas which filled his mind at that time. Engel succeeded in bringing a systematic order to this chaotic mass of thought."

After returning to Leipzig, Engel finished his Habilitation titled "On the defining equations of the continuous transformation groups" and became a Privatdozent.

In 1886, Klein moved to Göttingen for various reasons. (See [18] for a brief description of Klein's career.) Thanks to the efforts of Klein, Lie moved to Leipzig in 1886 to take up a chair in geometry. More description of this will be given in $\S 8$ below.

When Lie visited Leipzig in February 1886 to prepare for his move, he wrote to his wife excitedly [27, p. 320], "to the best of my knowledge, there have been no other foreigners, other than Abel and I, appointed professor at a German University. (The Swiss are out of the calculation here.) It is rather amazing. In Christiania I have often felt myself to be treated unfairly, so I have truly achieved an unmerited honor."

Leipzig was the hometown of the famous Leibniz and a major culture and academic center. In comparison to his native country, it was an academic heaven for Lie.

In April 1886, Lie became the Professor of Geometry and Director of the Mathematical Seminar and Institute at the University of Leipzig. Lie and Engel resumed to work intensively on their joint book again. In 1888, the leading German scientific publisher Teubner, based in Leipzig, published the first volume of Theory of transformation groups, which was 632 pages long.

In that year, Engel also became the assistant to Lie after Friedrich Schur left. When Lie went to a nerve clinic near the end of 1889, Engel gave Lie's lectures for him.

The second volume of their joint book was published in 1890 and was 555 pages long, and the third volume contained 831 pages and was published in 1893.

The three big volumes of joint books with Engel would not see the light of day or even start without the substantial contribution of Engel.

It was a major piece of work. In a 21-page review of the first volume [9, p. 16], Eduard Study wrote,

The work in question gives a comprehensive description of an extensive theory which Mr. Lie has developed over a number of years in a large number of individual articles in journals... Because most of these articles are not well known, and because of their concise format, the content, in 
spite of its enormous value, has remained virtually unknown to the scientific community. But by the same token we can also be thankful that the author has had the rare opportunity of being able to let his thoughts mature in peace, to form them in harmony and think them through independently, away from the breathless competitiveness of our time. We do not have a textbook written by a host of authors who have worked together to introduce their theories to wider audience, but rather the creation of one man, an original work which, from beginning to end, deals with completely new things [...] We do not believe that we are saying too much when we claim that there are few areas of mathematical science which will not be enriched by the fundamental ideas of this new discipline.

It is probably interesting to note that Engel's role and effort in this massive work were not mentioned here. Maybe the help of a junior author or assistant was taken for granted in the German culture at that time.

In the preface to the third volume, Lie wrote [9, p. 15]:

For me, Professor Engel occupies a special position. On the initiative of F. Klein and A. Mayer, he traveled to Christiania in 1884 to assist me in the preparation of a coherent description of my theories. He tackled this assignment, the size of which was not known at that time, with the perseverance and skill which typifies a man of his caliber. He has also, during this time, developed a series of important ideas of his own, but has in a most unselfish manner declined to describe them here in any great detail or continuity, satisfying himself with submitting short pieces to Mathematische Annalen and, particularly, Leipziger Berichte. He has, instead, unceasingly dedicated his talent and free time which his teaching allowed him to spend, to work on the presentation of my theories as fully, as completely and systematically, and above all, as precisely as is in any manner possible. For this selfless work which has stretched over a period of nine years, I, and, in my opinion, the entire scientific world owe him the highest gratitude.

Lie and Engel formed a team both in terms of writing and teaching. Some students came to study with both Lie and Engel. Engel also contributed to the success of Lie's teaching. For example, a major portion of students who received the doctoral degree at Leipzig was supervised under Lie. Lie also thanked Engel for this in the preface of the third volume.

But this preface also contained a description of some conflict with Klein, and hence Engel's academic future suffered due to this. See $§ 9$ for more detail.

\section{Lie's Breakdown and a Final Major Result}

After his move to Leipzig, Lie worked hard and was very productive. While Leipzig was academically stimulating to Lie, it was not stress-free for him, and relations with others were complicated too. "The pressure of work, problems of collaboration, and do- mestic anxieties made him sleepless and depressed, and in 1889 he had a complete breakdown" [27, p. 328]. Lie had to go to a nerve clinic and stayed there for seven months. He was given opium, but the treatment was not effective, and he decided to cure the problem himself. ${ }^{4}$ He wrote to his friend [26, XXIII]:

In the end I began to sleep badly and finally did not sleep at all. I had to give up my lecturing and enter a nerve clinic. Unfortunately I have been an impossible patient. It has always been my belief that the doctors did not understand my illness. I have been treated with opium, in enormous dose, to calm my nerves, but it did not help. Also sleeping draughts. Three to four weeks ago I got tired of staying at the nerve clinic. I decided to try to see what I could do myself to regain my equilibrium and the ability to sleep. I have now done what the doctors say no one can endure, that is to say I have completely stopped taking opium. It has been a great strain. But now, on a couple of days, against the doctors' advice, I have taken some exercise.

I hope now that in a week's time I shall have completely overcome the harmful effects of the opium cure. I think myself that the doctors have only harmed me with opium.

My nerves are very strained, but my body has still retained its horsepower. I shall cure myself on my own. I shall walk from morning to evening (the doctors say it is madness). In this way I shall drive out all the filth of the opium, and afterwards my natural ability to sleep will gradually return. That is my hope.

Finally he thought that he had recovered, and was released. Actually he was not cured at the time of release. Instead, in the reception book of the clinic, his condition at that time was recorded as "a Melancholy not cured" [27, p. 328]. His friends and colleagues found changes in Lie's attitudes towards others and his behaviors: mistrusting and accusing others for stealing his ideas. Indeed, according to Engel [27, p. 397], Lie did recover his mathematical ability, but "not as a human being. His mistrust and irritability did not dissipate, but rather they grew more and more with the years, such that he made life difficult for himself and all his friends. The most painful thing was that he never allowed himself to speak openly about the reasons for his despondency."

When he was busy teaching and working out his results, he did not have much time to pick up new topics. While at the nerve clinic, he worked again on the so-called Helmholtz problem on the axioms of geometry $^{5}$ and wrote two papers about it.

\footnotetext{
4 According to the now accepted theory, Lie suffered from the so-called pernicious anemia psychosis, an incurable disease at that time. People also believe that his soured relations with Klein and others were partly caused by this disease. See the section on the period 1886-1898 in [9] and the reference [29] there.

${ }^{5}$ Lie's work on the Helmholtz problem was apparently well known at the beginning of the 20th century. According to [5, Theorem 16.7], the Lie-Helmholtz Theorem states that
} 
Lie had thought of and worked on this problem for a long time and had also criticized the work of Helmholtz and complained to Klein about it. According to [27, pp. 380-381],

Very early on, Lie was certainly clear that the transformation theory he was developing, was related to non-Euclidean geometry, and in a letter to Mayer as early as 1875 , Lie had pointed out that von Helmhotz's work on the axioms of geometry from 1868 , were basically and fundamentally an investigation of a class of transformation groups: "I have long assumed this, and finally had it verified by reading his work."

Klein too, in 1883, has asked Lie what he thought of von Helmhotz's geometric work. Lie replied immediately that he found the results correct, but that von Helmhotz operated with a division between the real and imaginary that was hardly appropriate. And a little later, after having studied the treatise more thoroughly, he communicated to Klein that von Helmhotz's work contained "substantial shortcomings", and he thought it positively impossible to overcome these shortcomings by means of the elementary methods that von Helmhotz had applied. Lie went on to complete and simplify von Helmhotz's spatial theory [...]

In 1884, Lie wrote to Klein [26, XXVI]:

If I ever get as far as to definitely complete my old calculations of all groups and point transformations of a three-dimensional space I shall discuss in more detail Helmholtz's hypothesis concerning metric geometry from a purely analytical aspect.

According to [27, p. 381],

Lie did further work with von Helmhotz's space problem, and confided to Klein in April 1887, that the earlier works on the problem had now come to a satisfying conclusion - at least when one was addressing finite dimensional transformation groups, and therein, a limited number of parameters. What remained was to deduce some that extended across the board such that infinite dimensional groups could be included.

Lie's work on the Helmholtz problem led him to being awarded the first Lobatschevsky prize in 1897. Klein wrote a very strong report on his work, and this report was the determining factor for this award.

\section{An Overview of Lie's Major Works}

As mentioned before, Lie was very productive and he wrote many thousands of pages of papers and multiple books. His name will be forever associated with Lie groups and Lie algebras and several other dozen concepts and definitions in mathematics (al-

spaces of constant curvature, i.e., the Euclidean space, the hyperbolic space and the sphere, can be characterized by abundance of isometries: for every two congruently ordered triples of points, there is an isometry of the space that moves one triple to the other, where two ordered triples of points $\left(v_{1}, v_{2}, v_{3}\right),\left(v_{1}^{\prime}, v_{2}^{\prime}, v_{3}^{\prime}\right)$ are congruent if the corresponding distances are equal, $d\left(v_{i}, v_{j}\right)=d\left(v_{i}^{\prime}, v_{j}^{\prime}\right)$ for all pairs $i, j$. References to papers of Weyl and Enriques on this theorem were given in [5]. most all of them involve Lie groups or Lie algebras in various ways). One natural question is what exactly Lie had achieved in Lie theory. The second natural question is: besides Lie groups and Lie algebras, what else Lie had done.

It is not easy to read and understand Lie's work due to his writing style. In a preface to a book of translations of some papers of Lie [21] in a book series Lie Groups: History, Frontiers and Applications, which contain also some classical books and papers by E. Cartan, Ricci, Levi-Civita and also other more modern ones, Robert Hermann wrote:
In reading Lie's work in preparation for my com- mentary on these translations, I was overwhelmed by the richness and beauty of the geometric ideas flowing from Lie's work. Only a small part of this has been absorbed into mainstream mathematics. He thought and wrote in grandiose terms, in a style that has now gone out of fashion, and that would be censored by our scientific journals! The papers translated here and in the succeeding vol- umes of our translations present Lie in his wildest and greatest form.

We nevertheless try to provide some short summaries. Though articles in Encyclopedia Britannica are targeting the educated public, articles about mathematicians often give fairly good summaries. It might be informative and interesting to take a look at such an article about Lie before the global theory of Lie groups were developed Weyl and Cartan. An article in Encyclopedia Britannica in 1911 summarized Lie's work on Lie theory up to that time:

\begin{abstract}
Lie's work exercised a great influence on the progress of mathematical science during the later decades of the 19th century. His primary aim has been declared to be the advancement and elaboration of the theory of differential equations, and it was with this end in view that he developed his theory of transformation groups, set forth in his Theorie der Transformationsgruppen (3 vols., Leipzig, 1888-1893), a work of wide range and great originality, by which probably his name is best known. A special application of his theory of continuous groups was to the general problem of non-Euclidean geometry. The latter part of the book above mentioned was devoted to a study of the foundations of geometry, considered from the standpoint of B. Riemann and H. von Helmholtz; and he intended to publish a systematic exposition of his geometrical investigations, in conjunction with Dr. G. Scheffers, but only one volume made its appearance (Geometrie der Berührungstransformationen, Leipzig, 1896).
\end{abstract}

The writer of this article in 1911 might not have imagined the wide scope and multifaceted applications of Lie theory. From what I have read and heard, a list of topics of major work of Lie is as follows:

1. Line complexes. This work of Lie was the foundation of Lie's future work on differential equations and transformation groups, and hence of Lie theory [13]. It also contains the origin of toric varieties. 
2. Lie sphere geometry and Lie contact structures. Contact transformations are closely related to contact geometry, which is in many ways an odddimensional counterpart of symplectic geometry, and has broad applications in physics. Relatively recently, it was applied to low-dimensional topology.

3. The integration theory of differential equations. This subject has died and recovered in a strong way in connection with integrable systems and hidden symmetries.

4. The theory of transformation groups (or Lie groups). This has had a huge impact through the development, maturing and applications of Lie groups. The theory of transformation groups reached its height in the 1960-1970s. But the theory of Lie groups is becoming more important with the passage of time and will probably stay as long as mathematics is practiced.

5. Infinitesimal transformation groups (or Lie algebras). Lie algebras are simpler than Lie groups and were at first used as tools to understand Lie groups, but they are important in their own right. For example, the infinite-dimensional KacMoody Lie algebras are natural generalizations of the usual finite dimensional Lie groups, and their importance and applications are now wellestablished. Though they also have the corresponding Kac-Moody Lie groups, it is not clear how useful they can be.

6. Substantial contribution to the Erlangen program, which was written and formally proposed by Felix Klein and whose success and influence was partially responsible for the breakup of the friendship between Lie and Klein. Lie contributed to the formulation and also the development of this program, and his role has been recognized more and more by both historians of mathematics and practicing mathematicians.

7. The Helmholtz space problem: determine geometries whose geometric properties are determined by the motion of rigid bodies. See footnote 4 . The solution of this problem led Lie to be awarded the Lobachevsky prize. Lie's work on this problem also had a big impact on Poincaré's work on geometry.

8. Minimal surfaces. In 1878 , building on the work of Monge on integration of the Euler-Lagrange equations for minimal surfaces, Lie assigned each minimal surface a complex-analytic curve. This was the starting point of a fruitful connection between minimal surfaces and analytic curves. Together with the work of Weierstrass, Riemann, Schwarz, and others, this introduced the wide use of methods and results of complex function theory in the theory of minimal surfaces at the end of the 19th century.

\section{Three Fundamental Theorems of Lie in the Lie Theory}

When people talk about Lie's work, they often mention three fundamental theorems of Lie. His second and third fundamental theorems are well known and stated in many textbooks on Lie theories. On the other hand, the first fundamental theorem is not mentioned in most books on Lie groups and Lie algebras. The discussion below will explain the reasons:

1. It addresses a basic problem in transformation group theory rather than a problem in abstract Lie theory.

2. It is such a basic result that people often take it for granted.

We will first discuss these theorems in the original setup of transformation groups and later summarize all three theorems in the modern language.

The first theorem says that a local group action on a manifold is determined by the induced vector fields on the manifold. Now the space of vector fields of the manifold forms a Lie algebra. So the study of Lie group actions is reduced to the study of Lie algebras.

This is a deep insight of Lie and is one of the reasons for people to say that Lie reduced the study of Lie groups to Lie algebras, and hence reduced a nonlinear object to a linear one.

In the case of a one-parameter group of local diffeomorphisms of a manifold, the action is determined by one vector field on the manifold. Conversely, given a vector field, the existence of the corresponding local solution should have been well known in Lie's time. The proper definition of manifold was not known then, but no notion of manifolds was needed since the action of Lie group actions in Lie's work is local and hence can be considered on $\mathbb{R}^{n}$.

In Lie's statement, the key point is to show how the vector fields on a manifold $M$ associated with a Lie group $G$ is determined by a homomorphism from $\mathfrak{g}=T_{e} G$ to the space $\chi(M)$ of vector fields on $M$. (One part of the theorem is that $\mathfrak{g}=T_{e} G$.)

Lie's second theorem says that given a Lie algebra homomorphism $\mathfrak{g}=T_{e} G \rightarrow \chi(M)$, then there is a local action. One important point is that there is already a Lie group $G$ whose Lie algebra is $\mathfrak{g}$.

One special case of Lie's Fundamental Theorems 1 and 2 is that a one-parameter group of diffeomorphisms $\varphi_{t}$ of a manifold $M$ amounts to a vector field $X$ on the manifold. This has two components:

1. The family $\varphi_{t}$ induces a vector field $X$ by taking the derivative, and $\varphi_{t}$ is uniquely determined by $X$. The uniqueness follows from the fact that $\varphi_{t}$ satisfies an ODE. 
2. Given a vector field $X$, there is an one-parameter family of local diffeomorphisms $\varphi_{t}$ which induces $X$. If $M$ is compact, then the diffeomorphisms $\varphi_{t}$ are global. This amounts to integrating a vector field on a manifold into a flow.

The third theorem says that given any abstract Lie algebra $\mathfrak{g}$, and a Lie algebra homomorphism $\mathfrak{g} \rightarrow \chi(M)$, then there is a local Lie group (or the germ of a Lie group) $G$ and an action of $G$ on $M$ which induces the homomorphism $\mathfrak{g} \rightarrow \chi(M)$.

Lie was interested in Lie group actions. Now people are more interested in the theory of abstract Lie groups and usually reformulate these results in terms of abstract Lie groups and Lie algebras.

If we generalize and put these three fundamental theorems in the modern language of Lie theory, then they can be stated as follows and can be found in most books on Lie groups and algebras:

1. The first theorem should be stated as: a Lie group homomorphism is determined locally by a Lie algebra homomorphism.

2. The second theorem says that any Lie group homomorphism induces a Lie algebra homomorphism. Conversely, given a Lie algebra homomorphism, there is a local group homomorphism between corresponding Lie groups. If the domain of the locally defined map is a simply connected Lie group, then there is a global Lie group homomorphism.

3. The third theorem says that given a Lie algebra $\mathfrak{g}$, there exists a Lie group $G$ whose Lie algebra is equal to $\mathfrak{g}$. (Note that there is no group action here and hence tis statement is different from the statements above.)

\section{Relation with Klein I: The Fruitful Cooperation}

There are many differences and similarities between Lie and Klein. Lie was a good natured, sincere great mathematician. For example, he gave free lectures in the summer to USA students to prepare them for his later formal lectures. He went out of his way to help his Ph.D. students. He was not formal, and his lectures were not polished and could be messy sometimes.

Klein was a good mathematician with a great vision and he was also a powerful politician in mathematics. He was a noble, strict gentleman. His lectures were always well-organized and polished.

Lie and Klein first met in Berlin in the winter semester of 1869-1870 and they became close friends. It is hard to over estimate the importance of their joint work and discussions on their mathematical works and careers. For example, it was Klein who helped Lie to see the analogy between his work on differential equations and Abel's work on the solvability of algebraic equation, which motivated Lie to develop a general theory of differential equations that is similar to the Galois theory for algebraic equations, which lead to Lie theory. On the other hand, it was Lie who provided substantial evidence to the general ideas in the Erlangen program of Klein that were influential on the development of that program.

Klein also helped to promote Lie's work and career in many ways. For example, when Klein left Leipzig, he secured the vacant chair for Lie in spite of many objections. Klein drafted the recommendation of the Royal Saxon Ministry for Cultural Affairs and Education in Dresden to the Philosophical Faculty of the University of Leipzig, and the comment on Lie run as follows [9, p. 12]:

\begin{abstract}
Lie is the only one who, by force of personality and in the originality of his thinking, is capable of establishing an independent school of geometry. We received proof of this when Kregel von Sternback's scholarship was to be awarded. We sent a young mathematician - our present Privatdocent, Dr. Engel - to Lie in Chtristiania, from where he returned with a plethora of new ideas.
\end{abstract}

It is also helpful to quote here a letter written by Weierstrass at that time [9, p. 12]:

\begin{abstract}
I cannot deny that Lie has produced his share of good work. But neither as a scholar nor as a teacher is he so important that there is a justification in preferring him, a foreigner, to all of those, our countrymen, who are available. It now seems that he is being seen as a second Abel who must be secured at any cost.
\end{abstract}

One particular fellow countryman Weierstrass had in mind was his former student Herman Schwarz, who was also a great mathematician.

Another crucial contribution of Klein to Lie's career was to send Engel to help Lie to write up his deep work on transformation groups. Without Engel, Lie's contributions might not have been so well known and hence might not have had the huge impacts on mathematics and physics that they have now. It is perhaps sad to note that Engel was punished by Klein in some way for being a co-author of Lie after the breakup between Lie and Klein. One further twist was that Klein made Engel edit Lie's collected works carefully after Lie passed away.

\section{Relation with Klein II: Conflicts and the Famous Preface}

The breakup between Lie and Klein is famous for one sentence Lie put down in the preface of the third volume of his joint book with Engel on Lie transformation groups published in 1893: "I am not a student of Klein, nor is the opposite the case, even if it perhaps comes closer to the truth." 
This is usually the only sentence that people quote and say. It sounds quite strong and surprising, but there are some reasons behind it. The issue is about the formulation and credit of ideas in the Erlangen program, which was already famous at that time. It might be helpful to quote more from the foreword of Lie [9, p. 19]:

F. Klein, whom I kept abreast of all my ideas during these years, was occasioned to develop similar viewpoints for discontinuous groups. In his Erlangen Program, where he reports on his and on my ideas, he, in addition, talks about groups which, according to my terminology, are neither continuous or discontinuous. For example, he speaks of the group of all Cremona transformations and of the group of distortions. The fact that there is an essential difference between these types of groups and the groups which I have called continuous (given the fact that my continuous groups can be defined with the help of differential equations) is something that has apparently escaped him. Also, there is almost no mention of the important concept of a differential invariant in Klein's program. Klein shares no credit for this concept, upon which a general invariant theory can be built, and it was from me that he learned that each and every group defined by differential equations determines differential invariants which can be found through integration of complete systems.

I feel these remarks are called for since Klein's students and friends have repeatedly represented the relationship between his work and my work wrongly. Moreover, some remarks which have accompanied the new editions of Klein's interesting program (so far, in four different journals) could be taken the wrong way. I am no student of Klein and neither is the opposite the case, though the latter might be closer to the truth.

By saying all this, of course, I do not mean to criticize Klein's original work in the theory of algebraic equations and function theory. I regard Klein's talent highly and will never forget the sympathetic interest he has taken in my research endeavors. Nonetheless, I don't believe he distinguishes sufficiently between induction and proof, between a concept and its use.

According to [27, p. 317], in the same preface,

Lie's assertion was that Klein did not clearly distinguish between the type of groups which were presented in the Erlangen Programme - for example, Cremonian transformations and the group of rotations, which in Lie's terminology were neither continuous nor discontinuous - and the groups Lie had later defined with the help of differential equations:

"One finds almost no sign of the important concept of differential invariants in Klein's program me. This concept, which first of all a common invariant theory could be build upon, is something Klein has no part of, and he has learned from me that every group that it defined by means of differential equations, determines differential invariants, which can be found through the integration of integrable systems."

...Lie continued, in their investigations of geometry's foundation, Klein, as well as von Helmhotz, de Tilly, Lindemann, and Killing, all committed gross errors, and this could largely be put down to their lack of knowledge of group theory.
Maybe some explanations are in order to shed more light on these strong words of Lie. According to [26, pp. XXIII-XXIV],

Sophus Lie gradually discovered that Felix Klein's support for his mathematical work no longer conformed with his own interests, and the relationship between the two friends became more reserved. When, in 1892, Felix Klein wanted to republish the Erlangen program and explain its history, he sent the manuscript to Sophus Lie for a comment. Sophus Lie was dismayed when he saw what Felix Klein has written, and got the impression that his friend now wanted to have his share of what Sophus Lie regarded as his life's work. To make things quite clear, he asked Felix Klein to let him borrow the letters he had sent him before the Erlangen program was written. When he learned that these letters no longer existed, Sophus Lie wrote to Felix Klein, November 1892.

The letter from Lie to Klein in November 1892 goes as follows [9, p. XXIV]:

I am reading through your manuscript very thoroughly. In the first place, I am afraid that you, on your part, will not succeed in producing a presentation that I can accept as correct. Even several points which I have already criticized sharply are incorrect, or at least misleading, in your current presentation. I shall try as far as possible to concentrate my criticism on specific points. If we do not succeed in reaching agreement, I think that it is only right and reasonable that we each present our views independently, and the mathematical public can then form their own opinion.

For the time being I can only say how sorry I am that you were capable of burning my so significant letters. In my eyes this was vandalism; I had received your specific promise that you would take care of them.

I have already told you that my period of naiveness is now over. Even if I still firmly retain good memories from the years 1869-1872, I shall nevertheless try to keep myself that which I regard as my own. It seems that you sometimes believe that you have shared my ideas by having made use of them.

The comprehensive biography of Lie [27, p. 371] gives other details on the origin of this conflict:

The relationship between them [Lie and Klein] had certainly cooled over recent years, although they continued to exchange letters the same way, although not as frequently as earlier. But it was above all professional divergencies that were central to the fact that Lie now broke off relationship. Following Lie's publication of the first volume of his Theorie der Transformationsgruppen, Klein judged that there was sufficient interest to have his Erlangen Programme been republished. But before Klein's text from 1872 was printed anew, Klein had contacted Lie to find out how the working relationship and exchange of ideas between them twenty years earlier should be presented. Lie had made violent objections to the way in which Klein had planned to portray the ideas and the work. But Klein's Erlangen Programme was printed, and it came out in four different journals, in German, Italian, English and French - without taking into account Lie' commentary on his assistance in formulating this twenty-year-old programme. More and more in mathematical circles, Klein's Erlangen Pro- 
gramme was spoken of as central to the paradigm shift in geometry that occurred in the previous generation. A large part of the third volume of Lie's great work on transformation groups was devoted to a deepening discussion on the hypotheses or axioms that ought to be set down as fundamental to a geometry, that - whether or not it accepted Euclid's postulates - satisfactorily clarified classical geometry as well as the non-Euclidean geometry of Gauss, Lobachevsky, Bolyai, and Riemann.

The information that spread regarding the relationship between Klein's and Lie's respective work, was, according to Lie, both wrong and misleading. Lie considered he had been side-lined but was eager to "set things right", and grasped the first and best opportunity. In front of the professional substance of his work he placed his twentypage foreword. The power-charge that liquidated their friendship and sent shock-waves through the mathematical milieu was short, if not sweet.

Klein was the king of German mathematics and probably also of the European mathematics at that time. What was people's reaction to the strong preface of Lie? Maybe a letter from Hilbert to Klein in 1893 will explain this [26, p. XXV]: "In his third volume, his megalomania spouts like flames."

Lie probably did not suffer too much professionally from this conflict with Klein since he had the chair at Leipzig. But this was not the case with Engel. Since Engel's name also appeared on the book, he had to pay for this. Engel was looking for a job, and a position of professorship was open at that time at the University of Königsberg, the hometown and home institution of Hilbert where he held a chair in mathematics, and this open position was a natural and likely choice for Engel. In the same letter to Klein, Hilbert continued [26, p. XXV], "I have excluded Engel completely. Although he himself has not made any comment in the preface, I hold him to some extent co-responsible for the incomprehensible and totally useless personal animosity which the third volume of Lie's work on transformation groups is full off."

Engel could not get an academic job for several years, ${ }^{6}$ and Klein arranged Engel to edit the collected works of Grassmann and then later the collected works of Lie; on the latter he worked for several decades.

Another consequence of this conflict with Klein was that Lie could not finish another proposed joint book with Engel on applications of transformation

\footnotetext{
6 On the other hand, all things ended well with Engel. In 1904, he accepted the chair of mathematics at the University of Greifswald when his friend Eduard Study resigned the chair, and in 1913, became the chair of mathematics at the University of Giessen. Engel also received a Lobachevsky Gold Medal. The Lobachevsky medal is different from the Lobatschevsky prize won by his mentor Lie and his fellow countryman Wilhelm Killing. The medal was given on a few occasions to the referee of a person nominated for the prize. For instance, Klein also received, in 1897, a the Gold medal, for his report on Lie. See [28].
}

groups to differential equations. According to [27, p. 390-391], after the publication of these three volumes,

\begin{abstract}
The next task that Lie saw for himself was to make refinements and applications of what had now been completely formulated. But this foreword [of the third volume] with its sharp accusations against Klein, caused hindrances to the further work. Because Lie in the same foreword had praised Engel to the skies for his "exact" and "unselfish activity", it now became difficult for Engel to continue to collaborate with Lie - consequently as well, nothing came of the announced work on, among other things, differential invariants and infinite dimensional continuous groups. As for Engel, his career outlook certainly now lay in other directions than Lie's. According to Lie's German student, Gerhard Kowalewski, relations between Lie and Engel gradually became so cool that they were seldom to be seen in the same place.
\end{abstract}

It should be pointed out that relations between Lie and Engel had some hard time before this foreword came out. It was caused by the fight between Lie and Killing due to some overlap in their work on Lie theories, in particular, Lie algebras. For some reason, at the initial stage, Killing communicated with Engel and cited some papers of Engel instead of Lie's, and Lie felt than Engel betrayed his trust. For a more detailed discussion on this issue, see [27, pp. 382-385, p. 395]. ${ }^{7}$ After Lie's death, Engel continued and carried out his mentor's work in several ways. See $\$ 11$ for example. He was a faithful disciple and was justly awarded with the Norwegian Order of St Olaf and an honorary doctorate from the University of Oslo.

Maybe there is one contributing factor to these conflicts. ${ }^{8}$ It is the intrinsic madness of all people who are devoted to research and are doing original work, in particular mathematicians and scientists. According to a comment of Lie's nephew, Johan Vogt, a pro-

7 Manfred Karbe pointed out that in his autobiography [20, pp. 51-52], Kowalewski speculates about the mounting alienation of Lie and Engel, and reports about Lie's dislike of his three-volume Transformation Groups. When Lie needed some stuff of his own in his lectures or seminars, he never made use of these books but only of the papers in Math. Ann. And Kowalewski continues on page 52, line -5:

"Von hier aus kann man es vielleicht verstehen, dass die Abneigung gegen das Buch sich auf den Mitarbeiter übertrug, dem er doch so sehr zu Dank verpflichtet war."

"From this one may perhaps understand that the aversion to the book is transferred to the collaborator to whom he was so much indebted."

8 There has been an explanation of Lie's behaviors in this conflict with Klein by establishing a relation between genius and madness. According to [27, p. 394], after Lie's death, "In Göttingen, Klein made a speech that gave rise to much rumor, not least because here, in addition to all his praise for his old friend, Klein suggested that the close relationship between genius and madness, and that Lie had certainly been struck by a mental condition that was tinged with a persecution complex - at least, by assessing the point form notes that Klein made for his speech, it seems that this was the expression he used." 
fessor at the University of Oslo in economics, and also a translator, writer and editor, made in 1930 on his uncle [27, p. 397],

We shall avail ourselves of a popular picture. Every person has within himself some normality and some of what may be called madness. I believe that most of my colleagues possess ninety-eight percent normality and two percent madness. But Sophus Lie certainly had appreciably more of the latter. The merging of a pronounced scientific gift and an impulsiveness that verges on the uncontrollable, would certainly describe many of the greatest mathematicians. In Sophus Lie this combination was starkly evident.

It might be helpful to point out that later at the request of the committee of Lobatschevsky prize, Klein wrote a very strong report about the important work of Lie contained in this third volume on transformation groups, and this report was instrumental in securing the inaugural Lobatschevsky prize for Lie.

It might also be helpful to quote from Klein on Lie's work related to this conflict. The following quote of Klein [19, pp. 352-353], its translation and information about it were kindly provided by Hubert Goenner:

I will now add a personal remark. The already mentioned Erlangen Program, is about an outlook which - as already stated in the program itself I developed in personal communication with Lie (now professor in Leipzig, before in Christiana). Lie who has been engaged particularly with transformation groups, created a whole theory of them, which finds its account in a larger œuvre "Theory of Transformation Groups", edited by Lie and Engel, Vol. I 1888, Vol. II 1890. In addition, a third volume will appear, supposedly in not all too distant a time. Obviously, we cannot think about responding now to the contents of Lie's theories [...] My remark is limited to having called attention to Lie's theories.

The above comment was made by Klein in the winter of 1889 or at the beginning of 1890, but Klein backed its publication until 1893, the year of the illfamed preface to the third volume by Lie and Engel.

Further details about this unfortunate conflict and the final reconciliation between these two old friends are also given in [27, pp. 384-394]. See also the article [18] for more information about Klein and on some related discussion on the relationship between Lie and Klein.

The above discussion showed that the success of the Erlangen program was one cause for the conflict between Lie and Klein. A natural question is how historians of mathematics have viewed this issue. Given the fame and impacts of the Erlangen program, it is not surprising that there have been many historical papers about it. Two papers [15] [3] present very different views on the contributions of Klein and Lie to the success and impacts of this program. The paper [15] argues convincingly that Lie's work in the period
1872-1892 made the Erlangen program a solid program with substantial results, while the paper [3] was written to dispute this point of view. It seems that the authors are talking about slightly different things. For example, [3] explains the influence of Klein and the later contribution of Study, Cartan and Weyl, but most of their contributions were made after 1890 . The analysis of the situation in [10, p. 550] seems to be fair and reasonable:

\begin{abstract}
It seems that the Erlangen Program met with a slow reception until the 1890 s, by which time Klein's status as a major mathematician at the University of Göttengen had a great deal to do with its successful re-launch. By that time too a number of mathematicians had done considerable work broadly in the spirit of the programme, although the extent to which they were influenced by the programme, or were even aware of it, is not at all clear [...] Since 1872 Lie had gone on to build up a vast theory of groups of continuous transformations of various kinds; but however much it owned to the early experiences with Klein, and however much Klein may have assisted Lie in achieving a major professorship at Leipzig University in 1886, it is doubtful if the Erlangen Program had guided Lie's thoughts. Lie was far too powerful and original a mathematician for that.
\end{abstract}

\section{Relations with Others}

As mentioned, both Klein and Engel played crucial roles in the academic life of Lie. Another important person to Lie is Georg Scheffers, who obtained his Ph.D. in 1890 under Lie. Lie thought highly of Scheffers. In a letter to Mittag-Leffler [27, p. 369], Lie wrote "One of my best pupils (Scheffers) is sending you a work, which he has prepared before my eyes, and who has taken his doctorate here in Leipzig with a dissertation that got the best mark... Scheffers possesses an unusually evident talent and his calculations are worked through with great precision, and bring new results."

After the collaboration between Lie and Engel unfortunately broke off, Scheffers substituted for Engel and edited two of Lie's lecture notes in the early 1890s. They are Lectures on differential equations with known infinitesimal transformations of 568 pages, and Lectures on Continuous groups of 810 pages. Later in 1896, they also wrote a book together, Geometry of contact transformations of 694 pages. All these book projects of Lie with others indicate that Lie might not be able to efficiently write up books by himself. For example, he only wrote by himself a book of 146 pages and a program for course in Christiania in 1878.

In 1896 Scheffers became docent at the Technical University of Darmstadt, where he was promoted to professor in 1900. The collaboration with Lie stopped after this move. From 1907 to 1935, when he retired, 
Scheffers was a professor at the Technical University of Berlin.

According to a prominent American mathematician, G. A. Miller, from the end of the nineteenth century, "The trait of Lie's character which impressed me most forcibly when I first met him in the summer of 1895 was his extreme openness and lack of effort to hide ignorance on any subject."

Though he was motivated by discontinuous groups (or rather finite groups) taught by Sylow and kept on studying a classical book on finite substitution groups by Jordan, he could never command the theory of finite groups. Miller continued, "In fact he frequently remarked during his lectures that he always got stuck when he entered upon the subject of discontinuous groups."

When Lie first arrived in Leipzig, teaching was a challenge for him due to both lack of students and the amount of time needed for preparation. In a letter to a friend from the youth, Lie wrote [26, p. XXI], "While, in Norway, I hardly spent five minutes a day on preparing the lectures, in Germany I had to spend an average of about 3 hours. The language is always a problem, and above all, the competition implies that I had to deliver 8-10 lectures a week."

When Lie and his assistant Engel decided to present their own research on transformation groups, students from all over the world poured in, and the Ecole Normale sent its best students to study with Lie. It was a big success. According to the recollection of a student of Lie [26, p. XXVII]:

\begin{abstract}
Lie liked to teach, especially when the subject was his own ideas. He had vivid contact with his students, who included many Americans, but also Frenchmen, Russians, Serbs and Greeks. It was his custom to ask us questions during the lectures and he usually addressed each of us by name.

Lie never wore a tie. His full beard covered the place where the tie would have been, so even the most splendid tie would not have shown to advantage. At the start of a lecture he would take off his collar with a deft movement, saying: "I love to be free", and he would then begin his lecture with the words "Gentlemen, be kind enough to show me your notes, to help me remember what I did last time". Someone or other on the front bench would immediately stand up and hold out the open notebook, whereupon Lie, with a satisfied nod of the bead, would say "Yes, now I remember". In the case of difficult problems, especially those referring to Lie's complex integration theories, it could happen that the great master, who naturally spoke without any kind of preparation whatsoever, got into difficulties and, as the saying goes, became stuck. He would then ask one of his elite students for help.
\end{abstract}

Lie had many students. Probably one of the most famous was Felix Hausdorff. Lie tried to convince Hausdorff to work with him on differential equations of the first order without success. Of course, Hausdorff became most famous for his work on topology.
See [27, pp. 392-393] for a description of Hausdorff and his interaction with Lie.

Throughout his life, Lie often felt that he was under-recognized and under-appreciated. This might be explained by his late start in mathematics and his early isolation in Norway. He paid careful attention to other people's reaction to his work. For example, Lie wrote about Darboux in a letter to Klein [25] in October 1882:

Darboux has studied my work with remarkable thoroughness. This is good insofar as he has given gradually more lectures on my theories at the Sorbonne, for example on line and sphere geometry, contact transformation, and first-order partial differential equations. The trouble is that he continually plunders my work. He makes inessential changes and then publishes these without mentioning my name.

\section{Collected Works of Lie: Editing, Commentaries and Publication}

Since Lie theories are so well known and there are many books on different aspects of Lie groups and Lie algebras, Lie's collected works are not so well known to general mathematicians and students. The editing and publication of Lie's collected works are both valuable and interesting to some people. In view of this, we include some relevant comments.

Due to his death at a relatively young age, the task of editing of Lie's work completelty fell on others. It turned out that editing and printing the collected work of Sophus Lie was highly nontrivial and a huge financial burden on the publisher. The situation is well explained in [6]:

Twenty-three years after the death of Sophus Lie appears the first volume to be printed of his collected memoirs. It is not that nothing has been done in the meantime towards making his work more readily available. A consideration of the matter was taken up soon after his death but dropped owing to the difficulties in the way of printing so large a collection as his memoirs will make. An early and unsuccessful effort to launch the enterprise was made by the officers of Videnskapsselskapet i Kristiania; but plans did not take a definite form till 1912; then through the Mathematischphysische Klasse der Leipziger Akademie and the publishing firm of B. G. Teubner steps were taken to launch the project. Teubner presented a plan for raising money by subscription to cover a part of the cost of the work and a little later invitations to subscribe were sent out. The responses were at first not encouraging; from Norway, the homeland of Lie, only three subscriptions were obtained in response to the first invitations.

In these circumstances, Engel, who was pressing the undertaking, resorted to an unusual means. He asked the help of the daily press of Norway. On March 9, 1913, the newspaper TIDENS TEGN of Christiania carried a short article by Engel with the title Sophus Lies samlede Afhandlinger in which was emphasized the failure of Lie's homeland to respond with assistance in the work of printing 
his collected memoirs. This attracted the attention of the editor and he took up the campaign: two important results came from this, namely, a list of subscriptions from Norway to support the undertaking and an appropriation by the Storthing to assist in the work. By June the amount of support received and promised was sufficient to cause Teubner to announce that the work could be undertaken; and in November the memoirs for the first volume were sent to the printer, the notes and supplementary matter to be supplied later.

The Great War so interfered with the undertaking that it could not be continued, and by the close of the war circumstances were so altered that the work could not proceed on the basis of the original subscriptions and understandings and new means for continuing the work had to be sought. Up to this time the work had been under the charge of Engel as editor. But it now became apparent that the publication of the memoirs would have to become a Norwegian undertaking. Accordingly, Poul Heegaard became associated with Engel as an editor. The printing of the work became an enterprise not of the publishers but of the societies which support them in this undertaking. Under such circumstances the third volume of the series, but the first one to be printed, has now been put into our hands. "The printing of further volumes will be carried through gradually as the necessary means are procured; more I cannot say about it," says Engel, "because the cost of printing continues to mount incessantly."

The first volume was published in 1922, and the sixth volume was published in 1937. The seventh volume consisted of some unpublished papers of Lie and was published only in 1960 due to the World War II and other issues. This was certainly a major collected work in the last 100 years.

The collected works of Lie are very well done with the utmost dedication and respect thanks to the efforts of Engel and Heegaard. This can be seen in the editor's introduction to volume VI of Lie's Collected Works,

If one should go through the whole history of mathematics, I believe that he will not find a second case where, from a few general thoughts, which at first sight do not appear promising, has been developed so extensive and wide-reaching a theory. Considered as an edifice of thought Lie's theory is a work of art which must stir up admiration and astonishment in every mathematician who penetrates it deeply. This work of art appears to me to be a production in every way comparable with that [...] of a Beethoven [...] It is therefore entirely comprehensible if Lie [...] was embittered that "deren Wesen, ja Existenz, den Mathematikern fort-während unbekannt zu sein scheint" (p. 680). This deplorable situation, which Lie himself felt so keenly, exists no longer, at least in Germany. In order to do whatever lies in my power to improve the situation still further, [...] I have sought to clarify all the individual matters (Einzelheiten) and all the brief suggestions in these memoirs.

Each volume contains a substantial amount of notes, commentaries and supplementary material such as letters of Lie, and "This additional material has been prepared with great care and with the convenience of the reader always in mind." For example, as mentioned before, Lie's first paper was only 8 pages long, but the commentary consisted of over 100 pages. According to [4],

Although Engel was himself an important and productive mathematician he has found his place in the history of mathematics mainly because he was the closest student and the indispensable assistant of a greater figure: Sophus Lie, after N. H. Abel the greatest Norwegian mathematician. Lie was not capable of giving to the ideas that flowed inexhaustibly from his geometrical intuition the overall coherence and precise analytical form they needed in order to become accessible to the mathematical world [...] Lie's peculiar nature made it necessary for his works to be elucidated by one who knew them intimately and thus Engel's "Annotations" completed in scope with the text itself.

\section{Acknowledgments}

I would like to thank Athanase Papadopoulos for carefully reading preliminary versions of this article and his help with references on the Lie-Helmholtz Theorem, and Hubert Goenner for several constructive and critical suggestions and references. I would also like to thank Manfred Karbe for the reference [20] and a summary of a possible explanation in [20] about alienation between Lie and Engel.

\section{References}

[1] M. A. Akivis, B. A. Rosenfeld, Elie Cartan (1869-1951). Translated from the Russian manuscript by V. V. Goldberg. Translations of Mathematical Monographs, 123. American Mathematical Society, Providence, RI, 1993.

[2] N. Baas, Sophus Lie. Math. Intelligencer 16 (1994), no. 1, 16-19.

[3] G. Birkhoff, M. K. Bennett, Felix Klein and his "Erlanger Programm", History and Philosophy of Modern Mathematics (Minneapolis, MN, 1985), 145-176, Minnesota Stud. Philos. Sci., XI. Univ. Minnesota Press, Minneapolis, MN, 1988.

[4] H. Boerner, Fredrich Engel, Complete Dictionary of Scientific Biography, Vol. 4. Charles Scribner's Sons, Detroit, 2008, pp. 370-371.

[5] H. Busemann, Local metric geometry. Trans. Amer. Math. Soc. 56 (1944), 200-274.

[6] R. Carmichael, Book Review: Sophus Lie's Gesammelte Abhandlungen, Bull. Amer. Math. Soc. 29 (1923), no. 8, 367-369; 31 (1925), no. 9-10, 559-560; 34 (1928), no. 3, 369-370; 36 (1930), no. 5, 337.

[7] S. S. Chern, Sophus Lie and differential geometry. The Sophus Lie Memorial Conference (Oslo, 1992), 129-137, Scand. Univ. Press, Oslo, 1994.

[8] G. Darboux, Sophus Lie. Bull. Amer. Math. Soc. 5 (1899), 367-370.

[9] B. Fritzsche, Sophus Lie: A sketch of his life and work. J. Lie Theory 9 (1999), no. 1, 1-38.

[10] J. Gray, Felix Klein's Erlangen Program, Comparative considerations of recent geometrical researches, Landmark Writings in Western Mathematics 1640-1940. Elsevier, 2005, pp. 544-552. 
[11] J. Gribbin, The Scientists: A History of Science Told Through the Lives of Its Greatest Inventors, Random House Trade Paperbacks, 2004.

[12] G. Halsted, Sophus Lie. Amer. Math. Monthly 6 (1899), no. 4, 97-101.

[13] T. Hawkins, The birth of Lie's theory of groups. The Sophus Lie Memorial Conference (Oslo, 1992), 23-50, Scand. Univ. Press, Oslo, 1994.

[14] T. Hawkins, Emergence of the Theory of Lie Groups. An Essay in the History of Mathematics 1869-1926. Sources and Studies in the History of Mathematics and Physical Sciences. Springer-Verlag, New York, 2000.

[15] T. Hawkins, The Erlanger Programm of Felix Klein: Reflections on its place in the history of mathematics. Historia Math. 11 (1984), no. 4, 442-470.

[16] S. Helgason, Sophus Lie, the mathematician. The Sophus Lie Memorial Conference (Oslo, 1992), 3-21, Scand. Univ. Press, Oslo, 1994.

[17] L. Ji, A summary of topics related to group actions, preprint, 2013, to appear in Handbook of Group Actions.

[18] L. Ji, Felix Klein: His life and mathematics, this volume.

[19] F. Klein, Nicht-Euklidische Geometrie, I. Vorlesung, Wintersemester 1889/90. Ausgearbeitet von F. Schilling, Göttingen, 1893.

[20] G. Kowalewski, Bestand und Wandel. Meine Lebenserinnerungen zugleich ein Beitrag zur neueren
Geschichte der Mathematik. Verlag Oldenbourg, München, 1950.

[21] S. Lie, Sophus Lie's 1880 Transformation Group Paper. In Part a Translation of "Theorie der Transformations gruppen" by S. Lie [Math. Ann. 16 (1880), 441-528]. Translated by Michael Ackerman. Comments by Robert Hermann. Lie Groups: History, Frontiers and Applications, Vol. I. Math Sci Press, Brookline, Mass., 1975.

[22] R. Merton, On the Shoulders of Giants: A Shandean Postscript, University of Chicago Press, 1993,

[23] G. Miller, Some reminiscences in regard to Sophus Lie. Amer. Math. Monthly 6 (1899), no. 8-9, 191-193.

[24] C. Reid, Hilbert. Reprint of the 1970 original. Copernicus, New York, 1996.

[25] D. Rowe, Three letters from Sophus Lie to Felix Klein on Parisian mathematics during the early 1880s. Translated from the German by the author. Math. Intelligencer 7 (1985), no. 3, 74-77.

[26] E. Strom, Sophus Lie, The Sophus Lie Memorial Conference (Oslo, 1992), Scand. Univ. Press, Oslo, 1994.

[27] A. Stubhaug, The Mathematician Sophus Lie. It Was the Audacity of My Thinking. Translated from the 2000 Norwegian original by Richard H. Daly. SpringerVerlag, Berlin, 2002.

[28] A. Vassilief, Prox Lobachevsky (premier concours). Nouv. Ann. Math., 3e sér. 17 (1898), 137-139. 